\begin{tabular}{|c|c|}
\hline \multirow{3}{*}{ 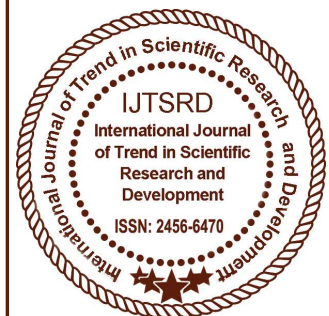 } & $\begin{array}{l}\text { International Journal of Trend in Scientific } \\
\text { Research and Development (IJTSRD) }\end{array}$ \\
\hline & International Open Access Journal \\
\hline & ISSN No: 2456 - 6470 | www.ijtsrd.com | Volume - 2 | Issue - 1 \\
\hline
\end{tabular}

\title{
Avoidance from Dengue by Microencapsulated with Vetiver root Essence with mosquito repellent finishing on Fabrics
}

\author{
Dr. B. Senthilkumar \\ Asst. Professor \\ Department of Rural Industries and Management, \\ Gandhigram Rural Institute, Deemed University, \\ Gandjigram - Dindigul, TamilNadu, India
}

\author{
D. Anita Rachel \\ Research Scholar \\ Department of Rural Industries and Management, \\ Gandhigram Rural Institute, Deemed University, \\ Gandjigram - Dindigul, TamilNadu, India
}

\begin{abstract}
Objective: This study was conducted to design the textile structured dress of knitted materials with mosquito repellent behavior using microencapsulated Vetiver root extract on a fabric to prevent from Dengue.
\end{abstract}

Methods: Vetiver root essence is extracted from (Vetiveriazizanioides) which is having high potential medical properties and it is one of the perennial grass, can be used to produce the very low cost and affordable medical products. The extract is taken by hydro distillation process, which was used as core and gum acacia was used as wall material. $20 \% \mathrm{~W} / \mathrm{V}$ gum acacia was allowed to swell with hot water and stirred well with temperature of $70{ }^{\circ} \mathrm{C}$. Further to this mixture $20 \mathrm{ml}$ of Vetiver root extract was mixed and stirred around 600rpm for $30 \mathrm{~min}$. Subsequent with this process $30 \% \mathrm{~V} / \mathrm{V}$ sodium sulphate was added then the stirrer speed was reduced $80 \mathrm{rpm}$ and then $5 \mathrm{ml}$ of $17 \%$ formaldehyde was added along with this mixture. Finally the microcapsules were obtained. Then this Vetiver root extract capsule mixture was coated on the Knitted and woven fabrics through Paddry-cure method and these materials can be used as Bed Spreads and Bed Sheets.

Results: Mosquito repellent study was carried out through Excito Chamber method and assessed in the terms of Mosquito repellence percentage. The maximum mosquito repellency percentage was obtained around 90\% wash durability, abrasion resistance; air permeability and busting strength of the coated textiles were also studied. SEM analysis and Gas Chromatography analysis were also done for the samples.

Conclusion: It was proved that Vetiver root extract capsule which is microencapsulated into textiles of the Knitted wear provide good resistance against mosquito bites and also concluded that this process is one of eco friendly process. This coated fabrics a can be used as dresses, Bed Spreads and Bed Sheets.

Keywords: Mosquito repellent in textile, Vetiver root extract, Cotton, Knitted Fabrics, Bed Spreads and Bed Sheets, microencapsulation Technique, Pad-drycure method

\section{Introduction}

Mosquitoes are the important vectors of diseases through transmitting pathogens. They are one of the primary causes for spreading diseases to the human being [1]. The genus Andes mosquitoes are the main causes for urban yellow fever in worldwide. Around 120 million people in the world have been infected due to mosquito bites and 4 million people are DENGUE. Another study, of the prevalence of dengue, estimates that 3.9 billion people, in 128 countries, are at risk of infection with dengue viruses Dengue fever is a mosquito-borne tropical disease caused by the dengue virus. ${ }^{[26]}$ Symptoms typically 
begin three to fourteen days after infection. ${ }^{[27]}$ This may include a high fever, headache, vomiting, muscle and joint pains, and a characteristic skin rash. Recovery generally takes two to seven days. ${ }^{[28]}$ In a small proportion of cases, the disease develops into the life-threatening dengue hemorrhagic fever, resulting in bleeding, low levels of blood platelets and blood plasma leakage, or into dengue shock syndrome, where dangerously low blood pressure occurs.

Dengue is spread by several species of mosquito of the Aedes type, principally $A$. aegypti. ${ }^{[1,26]}$ The virus has five different types; ${ }^{[7][8]}$ infection with one type usually gives lifelong immunity to that type, but only short-term immunity to the others. ${ }^{[1]}$ Subsequent infection with a different type increases the risk of severe complications. ${ }^{[1]}$ A number of tests are available to confirm the diagnosis including detecting antibodies to the virus or its RNA. ${ }^{[2]}$

Dengue has become a global problem since the Second World War and is common in more than 110 countries. ${ }^{[9][10]}$ Each year between 50 and 528 million people are infected and approximately 10,000 to 20,000 die. ${ }^{[1][5][6][12]}$ The earliest descriptions of an outbreak date from 1779. ${ }^{[10]}$ Its viral cause and spread were understood by the early 20th century. ${ }^{[13]}$ Apart from eliminating the mosquitoes, work is ongoing for medication targeted directly at the virus. ${ }^{[14]}$ Few of the Arthropod borne diseases are preventable through vaccines but not in the case of diseases like malaria and Dengue. So avoiding Mosquito bites are the only way to protect the individual from these diseases[3].At present the personal protective measures are taken from mosquito bites through applying mosquito repellant as skins lotions, coils, creams and liquidators are providing limited support[4]. Coating of suitable mosquito repellant over the clothing is an innovative method to avoid mosquito bites as the large portion of human body is coved [5]. This has necessitated the development of mosquito repellent fabrics. It is one of the revolutionary way to produce the coated mosquito repellent clothes has a capacity of driving away the mosquitoes [6]. Mostly Synthetic chemical larvicides applied for controlling mosquitoes but most of these coating are toxic to human. Therefore, researchers are currently exploiting natural eco-friendly substances as insecticides for controlling larval mosquitoes [7]. Various eco-friendly natural oils have been reported as mosquito repellents due to their eco-friendly and biodegradable nature such as citronella, cedar, verbena, pennyroyal, geranium, lavender, pine, cajeput, cinnamon, rosemary , basil, thyme, allspice, garlic, and peppermint[8]. Petroleum ether and methanol extracts of V.negundo show significant reduction of consumption and utilization of food and thereby bring about antifeedancy to $\mathrm{T}$. castaneum [9].In general Microencapsulation technology increases the durability of textile coating. A Microcapsule can store certain amount of functional agent and protective shield from the effects of moisture and sun light. This functional agent is diffused through the wall of the capsule in a regular interval, so that this technology could provide the durable finish to the textile substrate [10]. Similar to that microencapsulated Anndrographispaniculta plant extracts treated cotton fabric showed Good antimicrobial activity and its wash durability also showed better performance [11]. This present research work intended to develop a mosquito repellent plan knitted fabric using vetiver roots extract.

\section{Materials\& Methods}

\subsection{Materials}

Vetiver extract was used a coating agent for mosquito repellant and purchased from $\mathrm{M} / \mathrm{S}$ Naga natural products, Dindigul, Tamil Nadu. Plan knitted single jersey cotton fabric of 240 GSM was scoured and bleached well with alkali and peroxide respectively. Gelatin and gum Arabic was used as shell formation compound, which was sourced from GVR enterprises, Madurai $100 \%$ low twisted cotton yarn is knitted through plain and rib knitted structures [12]. Both the fabrics were scoured and bleached with sodium hydroxide and hydrogen peroxide respectively subsequently dyeing was carried out using hot brand reactive dye.

\subsection{Preparation of microcapsules:}

Mosquito repellent treatment was approached through microencapsulation technic over cotton knitted fabric. Vetiver roots extracted from Cymbopogoncitratus by hydro distillation process [13].It was used as core material gum acacia was used as wall material. $10 \%$ $\mathrm{W} / \mathrm{V}$ gum acacia was allowed to swell with hot water. To this mixture, $50 \mathrm{ml}$ of hot water was added and stirred well with temperature of $70{ }^{\circ} \mathrm{C}$. Further to this mixture $20 \mathrm{ml}$ of vetiver root extract was mixed and stirrer speed was maintained around 600rpm for 30 min. Followed by this process $20 \% \mathrm{~V} / \mathrm{V}$ sodium sulphate was added then the stirrer speed was reduced $80 \mathrm{rpm}$ and then $5 \mathrm{ml}$ of $17 \%$ formaldehyde was added 
along with this mixture. The microcapsules were obtained by decantation and washed with isopropyl alcohol followed by drying at the temperature of $45^{\circ} \mathrm{C}$ for $12 \mathrm{hrs}$

\subsection{Coating process over knitted fabric:}

The vetiver root extract capsule mixture was coated on the fabric through pad dry cure method. As reported by Golji the finishing of this agent through binder compound such as polyurethane ,acrylic to fix the micro capsule over the surface of the fabric, which enable the last longing effect[13]. A finishing bath was prepared with prepared microsules, $15 \% \mathrm{~V} / \mathrm{V}$ of acrylic crosslinking agent and remaining quantity of softener (Perisoft Nano, Bayer). The cotton knitted and woven fabric was immersed in this solution pneumatic padding mangle, squeezed and then dried at $80-85^{\circ} \mathrm{C}$ in an oven

\section{Characterization}

\subsection{Mosquito repellency testing:}

The mosquito repellent activity was tested through Excito Chamber method (Roberts, D, et al ,1997).with Anopheles variety of mosquito's Specially designed two-excitorepellency test chambers were used to evaluate the efficiency of repellency activity. The wooden outer chamber of excito-repellency testing device measures $34 \mathrm{~cm} \times 32 \mathrm{~cm} \times 32 \mathrm{~cm}$ and faces the front panel with the single escape portal. The mosquito escape zone consists of an outward projecting funnel with the dimension of $14 \mathrm{~cm}$ long in its top and bottom exit funnel, leaving $1.5 \mathrm{~cm}$ wide (a horizontal slit) through which mosquitos can escape from the chamber. The back size of the metal door is hinged metal door, which tightly closed. The back side consists of mosquito exposure zone having is a hinged metal door, which is also contains an inner removable panel. This panel fits inside the back of the exposure chamber, in addition to this 4 small flanges were available along with this chamber to serve the imprison the mosquitos. The plexiglass helps to observe the mosquito's population inside the chamber.

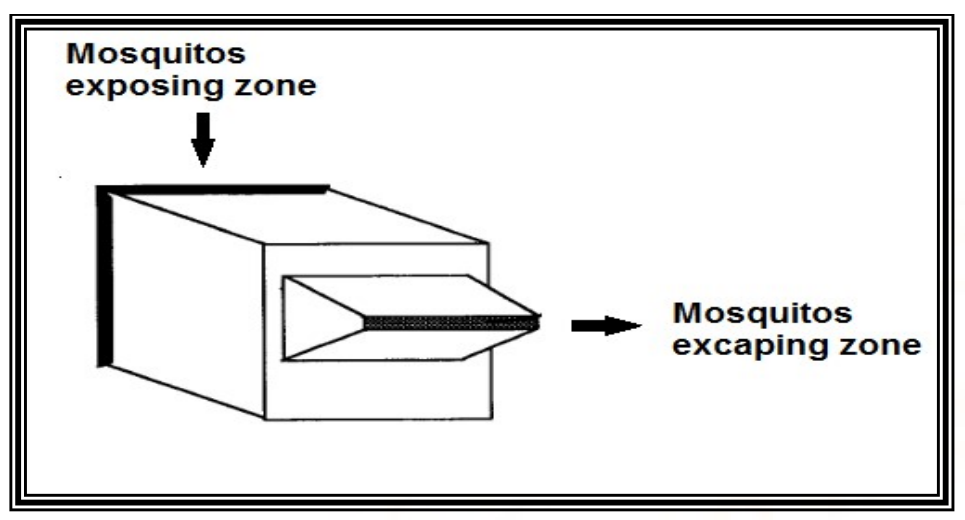

Fig. 1.Excito chamber used for Mosquito repellence testing [14].

This test consists of 4 group of 25 mosquitoes were introduced in to this chamber for one minute. Before conducting the experiments Mosquitoes were deprived of all nutrition and water for a minimum of 4 hours before exposure. Laboratory tests were performed during daylight hours only. Before initiating the testing procedure the exit funnels were sealed and mosquitos were permitted exposure in to the chamber without test specimen, which ensures the mosquitoes to adjust the test chamber condition and funnel was opened then the mosquito repellent treated fabric was kept in to the chamber and one by one all the group of 25 mosquitos were exposed in the chamber for one minute. Number of escaping mosquitos from the chamber was recorded manually at 1 min intervals of 5 min of observation. A survival analysis approach was used to estimate the rates of mosquitoes escaping from chambers. In the excitorepellency test, there are only 2 possible outcomes for a specimen: it will either escape or not escape from the exposure chamber (Mosquitos escaped are treated as death).

\subsection{Wash durability analysis}

As per the AATCC-124-2009 the samples were washed in a front loading washing machine in a 5\% neutral soap solution for 20 minutes and dried. This process was repeated 10 washes, 20 washes and 30 washes for the microencapsulated samples. Mosquito repellency test was carried out for all the samples, which ensured the wash durability of the coated samples of knitted fabrics.

\subsection{Scanning Electron microscopy (SEM)}

SEM analysis was done to inspect the morphology of coated knitted fabric. The textile sample treated with microencapsulated mosquito repellent coating supposed to form a rough coating over the fibre 
surface of the clothing. The imaging was done with $500 \mathrm{X}$ and 2000X magnification at $5 \mathrm{kV}$.

\subsection{Gas Chromatography mass spectrum (GC-MS) analysis}

The component identification of the vetiver root extract was done by GC-MS analysis and the spectral data of the sample was investigated. After the sample was subjected to washing, the analysis was carried out using Hawlett Packard GC-MS system, which consisted of a model 5890A gas chromatograph, a model 5970 mass selective detector, a HP 5970C MS chemstation, and a HP 7946 disc drive. Afuced silica capillary column coated with HP-5 cross linked 5\% phenylmethylsilicone (SE-54, $0.33 \mathrm{~mm}$ film thickness) was used. The GC temperature schedule was as follows: Initial temperature was $100^{\circ} \mathrm{c}$, for 1 $\min$, increased to $130{ }^{\circ} \mathrm{C}$ at the rate of $2^{\circ} \mathrm{C} / \mathrm{min}$, then increased to $200^{\circ} \mathrm{C}$ at the rate of $3{ }^{\circ} \mathrm{C} / \mathrm{min}$, finally increased to $280^{\circ} \mathrm{C}$ at the rate of $6^{\circ} \mathrm{C} / \mathrm{min}$ for $10 \mathrm{~min}$. The split ratio of $1: 12$, injection temperature was $250^{\circ} \mathrm{C}$, transfer line temperature was $270^{\circ} \mathrm{C}$ and iron source temperature was $200^{\circ} \mathrm{C}$. The mass spectrometer was operated at $70 \mathrm{eV}$ in the electron impact mode with SCAN or selected ion monitoring (SIM).Once the sample is presented in the vial, the microcapsules were tripped due to simultaneous pressing with the rod, before closing the vial. The volatile component in the capsule spread out in the gas phase until the headspace reaches a balance. It was studied for the period of $24 \mathrm{hrs}$. Subsequent to this testing, $0.5 \mathrm{~mL}$ of headspace gas was collected and injected with GC-FID equipment for further analysis.

\subsection{Abrasion resistance}

Abrasion resistance was tested using Martindale abrasion tester. This tester gives a controlled amount of abrasion between fabric surfaces at comparatively low pressure environment. A circular specimen of fabric was abraded with simple harmonic motion. The resistance of abrasion was estimated by finding the loss in mass of the specimen.

\subsection{Bursting strength}

It is the measure of pressure required to rupture a fabric. The selected busting strength tester working under the hydraulic bursting .According to IS013938-1 standard, the testing was executed. The sample tested will be clamped over the testing diaphragm and clamped with ring. The amount pressure exerted on the sample for busting through diaphragm was measured.

\subsection{Air permeability}

This testing was carried out with digital air permeability tester. The working principle of this instrument is that air is drawn through a specified area of the fabric, which is adjustable to suit specific textiles being evaluated.

\section{Results and discussion}

\subsection{Mosquito repellency}

The percentage was assessed through percentage of insects dead due to mosquito repellent treated fabric was calculated using the equation (1).The analysis was conducted in three different samples such as controlled sample, Vetiver root extract encapsulated fabric before wash, Vetiver root extract encapsulated fabric after 10 wash, Vetiver root extract encapsulated fabric after 20 wash, Vetiver root extract encapsulated fabric after 30 wash. The consolidated report of mosquito repellent activity was shown in table no. 1 
International Journal of Trend in Scientific Research and Development (IJTSRD) ISSN: 2456-6470

Table .1 Mosquito repellent activities of various stages of Vetiver root extract encapsulated cotton knitted fabric

\begin{tabular}{|c|c|c|c|c|c|c|}
\hline Fabric & Samples & $\begin{array}{c}\text { Specimens } \\
\text { Exposed } \\
\text { (Nos) }\end{array}$ & $\begin{array}{c}\text { Specimens } \\
\text { in the cage } \\
\text { (Nos) }\end{array}$ & $\begin{array}{c}\text { Specimens } \\
\text { Escaped(Nos) }\end{array}$ & $\begin{array}{l}\text { Specimens } \\
\text { dead (Nos) }\end{array}$ & $\begin{array}{l}\text { Mosquito } \\
\text { repellency } \\
\text { percentage }\end{array}$ \\
\hline 1 & \multirow{5}{*}{$\begin{array}{l}\text { Controlled } \\
\text { sample }\end{array}$} & 25 & 25 & 0 & 0 & 0 \\
\hline 2 & & 25 & 25 & 0 & 0 & 0 \\
\hline 3 & & 25 & 25 & 0 & 0 & 0 \\
\hline 4 & & 25 & 25 & 0 & 0 & 0 \\
\hline 5 & & 25 & 25 & 0 & 0 & 0 \\
\hline 1 & \multirow{5}{*}{$\begin{array}{l}\text { Vetiver root } \\
\text { extract } \\
\text { encapsulate }\end{array}$} & 25 & 2 & 9 & 14 & 92 \\
\hline 2 & & 25 & 1 & 5 & 19 & 96 \\
\hline 3 & & 25 & 4 & 6 & 15 & 84 \\
\hline 4 & & 25 & 3 & 9 & 13 & 88 \\
\hline 5 & & 25 & 3 & 10 & 12 & 88 \\
\hline 1 & \multirow{5}{*}{$\begin{array}{l}\text { Vetiver root } \\
\text { extract } \\
\text { encapsulate - } \\
10 \text { wash }\end{array}$} & 25 & 4 & 9 & 12 & 84 \\
\hline 2 & & 25 & 7 & 10 & 8 & 72 \\
\hline 3 & & 25 & 8 & 11 & 6 & 68 \\
\hline 4 & & 25 & 8 & 10 & 7 & 68 \\
\hline 5 & & 25 & 9 & 10 & 6 & 64 \\
\hline 1 & \multirow{5}{*}{$\begin{array}{l}\text { Vetiver root } \\
\text { extract } \\
\text { encapsulate - } \\
20 \text { wash }\end{array}$} & 25 & 10 & 5 & 10 & 60 \\
\hline 2 & & 25 & 9 & 10 & 6 & 64 \\
\hline 3 & & 25 & 10 & 7 & 8 & 60 \\
\hline 4 & & 25 & 8 & 5 & 12 & 68 \\
\hline 5 & & 25 & 9 & 6 & 10 & 64 \\
\hline 1 & \multirow{5}{*}{$\begin{array}{l}\text { Vetiver root } \\
\text { extract } \\
\text { encapsulate - } \\
30 \text { wash }\end{array}$} & 25 & 11 & 4 & 10 & 56 \\
\hline 2 & & 25 & 8 & 5 & 12 & 68 \\
\hline 3 & & 25 & 9 & 10 & 6 & 64 \\
\hline 4 & & 25 & 8 & 7 & 10 & 68 \\
\hline 5 & & 25 & 9 & 10 & 6 & 64 \\
\hline
\end{tabular}

From the analysis, it is clear that the controlled samples showed no repellent activity against mosquitoes. Whereas mosquito repellent encapsulated sample (prior to washing) generated higher level of mosquito repellent activity as compare with other samples. The anova study was carried out to measure the statistical significant between these samples. It is understood that Their difference between other sample is statistically significant $(\mathrm{F}=26.148, \mathrm{p}=0.00)$. Samples such as Vetiver root extract encapsulated fabric after 10 wash, Vetiver root extract encapsulated fabric after 20 wash, Vetiver root extract encapsulated fabric after 30 wash are shown slightly poor performance as compare with unwashed samples due to its loss of activity during washing. In post Hoc analysis it is understood that the difference between these three samples are statistically insignificant $(\mathrm{P}$ values between these samples are $0.126,0.188,0.995$ )

\subsection{Surface analysis of microencapsulated fabric}

The knitted cotton fabric after microencapsulated with Vetiver root extract was analysed through SEM analysis. Figures 3 and 4 show the surface effect of treated fabric with different magnification level. In both the figure particles were no longer visible on the surface but a thin layer covered with the fibre surface.

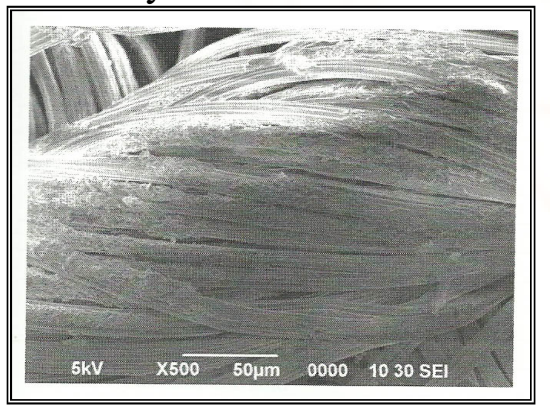

Fig.2 Scanning electron microphotograph of Vetiver root extract coated knitted fabric magnified $x 500$ 


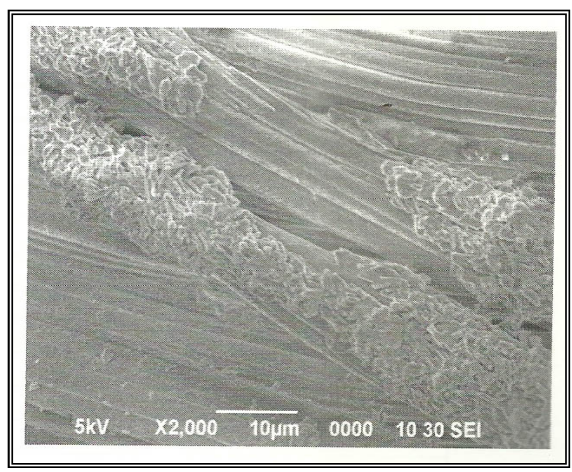

Fig.3 Scanning electron microphotograph of Vetiver root extract coated knitted fabric magnified $x 2000$

\subsection{Gas Chromatography analysis}

The chemical component identification of Vetiver root extract was done by GC-MS analysis and the spectral data of these identified compounds were interpreted. The fig. 4 shows that 37 compounds and the chromatogram showed 47 peeks within the retention time of $6.69 \mathrm{~min}$ to $46.94 \mathrm{~min}$. The major compound identified as 9,12-octadecadienoic acid(Z,Z) with around $15 \%$ and $n$-hexadeconic acid with $11.9 \%$ and lanosterol with $8 \%$.It is understood that from GC-MS analysis the lemon extract compound were confirmed.

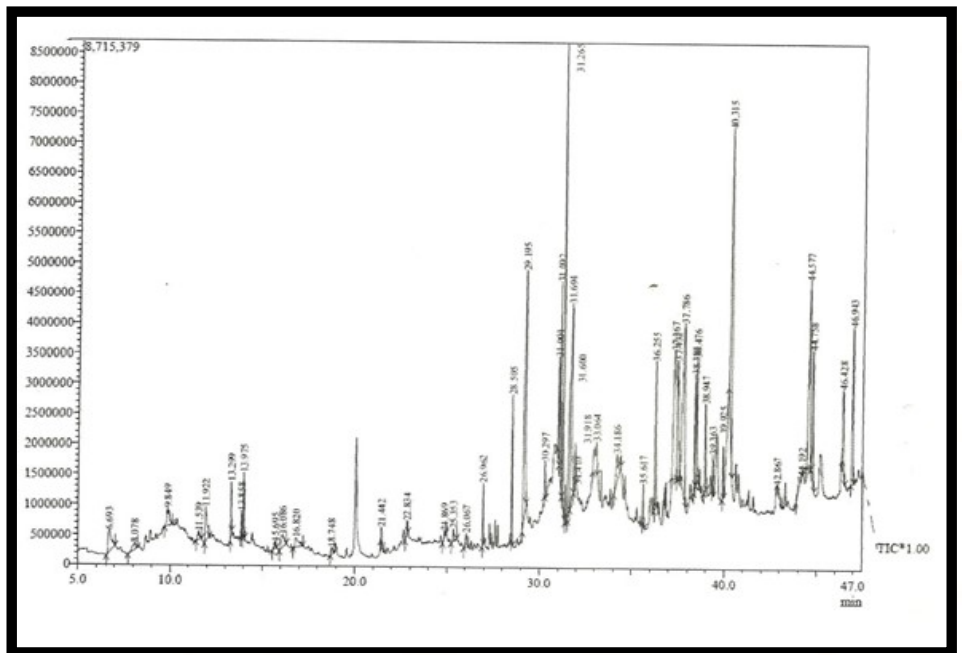

Fig 4. Chromatogram of GC-MS analysis of lemon grass extract

\subsection{Comparative analysis of abrasion resistance of the mosquito repellent coated samples}

The following table 2 shows the abrasion resistance of various mosquito repellent coated samples

Table 2. Abrasion resistance of mosquito repellent finished samples

\begin{tabular}{|c|c|c|c|}
\hline Fabric sample & $\begin{array}{c}\text { Weight } \\
\text { before } \\
\text { abrasion }\end{array}$ & $\begin{array}{c}\text { Weight after } \\
\text { abrasion }\end{array}$ & Weight loss(\%) \\
\hline Untreated sample & 5.15 & 5.06 & 1.75 \\
\hline $\begin{array}{c}\text { Vetiver root extract } \\
\text { encapsulated }\end{array}$ & 5.10 & 5.00 & 1.96 \\
\hline $\begin{array}{c}\text { Vetiver root extract } \\
\text { encapsulate -10 wash }\end{array}$ & 5.18 & 5.10 & 1.94 \\
\hline $\begin{array}{c}\text { Vetiver root extract } \\
\text { encapsulate - 20 wash }\end{array}$ & 5.16 & 5.06 & 2.14 \\
\hline $\begin{array}{c}\text { Vetiver root extract } \\
\text { encapsulate - 30 wash }\end{array}$ & 5.13 & 5.02 & $\mathbf{1 . 8 6 6 0}$ \\
\hline \multicolumn{2}{c}{ Mean } & $\mathbf{0 . 0 0 0}$ \\
\hline
\end{tabular}

From the table it is observed that lemongrass coated sample after 30 wash showed least performance than other samples but from the statistical point of view it is evident that the difference between the samples were insignificant (Since $\mathrm{P}<0.005$ ) 


\subsection{Bursting strength analysis}

The following table 3 shows the bursting strength of various mosquito repellent coated samples

Table 3. Bursting strength of the mosquito repellent finished samples

\begin{tabular}{|c|c|}
\hline Fabric sample & Bursting strength $(\mathrm{kg} / \mathrm{sq} \cdot \mathrm{cm})$ \\
\hline Untreated sample & $6.24 \pm 0.11$ \\
\hline Vetiver root extract encapsulated & $5.65 \pm .09$ \\
\hline $\begin{array}{c}\text { Vetiver root extract encapsulate after } \\
\text { 10 wash }\end{array}$ & $5.90 \pm 0.05$ \\
\hline $\begin{array}{c}\text { Vetiver root extract encapsulate after } \\
\text { 20 wash }\end{array}$ & $5.65 \pm 0.08$ \\
\hline $\begin{array}{c}\text { Vetiver root extract encapsulate after } \\
\text { 30 }\end{array}$ & $5.20 \pm 0.04$ \\
\hline
\end{tabular}

From the table it is observed that controlled sample showed highest bursting strength performance than other samples. It is interpreted that the surface coating covers the air passage over the surface of the fabric and extensibility of the fiber/yarn is also get affected due to the outer coating of Vetiver root extract, which reduces the bursting strength of the coated fabric.

\subsection{Air permeability analysis}

The following table 4 shows the air permeability of various mosquito repellent coated samples

Table 4.Airpermeability and porosity of the mosquito repellent finished samples

\begin{tabular}{|c|c|c|}
\hline Fabric sample & $\begin{array}{c}\text { Air permeability } \\
\left(\mathrm{cm}^{3} / \mathrm{cm}^{2} / \mathrm{s}\right)\end{array}$ & Porosity (\%) \\
\hline Untreated sample & $244.75 \pm 0.30$ & 86.24 \\
\hline $\begin{array}{c}\text { Vetiver root extract } \\
\text { encapsulated }\end{array}$ & $245.23 \pm 0.31$ & 84.36 \\
\hline $\begin{array}{c}\text { Vetiver root extract } \\
\text { encapsulate after 10 } \\
\text { wash }\end{array}$ & $245.83 \pm 0.29$ & 84.75 \\
\hline $\begin{array}{c}\text { Vetiver root extract } \\
\text { encapsulate after 20 } \\
\text { wash }\end{array}$ & $244.95 \pm 0.29$ & 86.18 \\
\hline $\begin{array}{c}\text { Vetiver root extract } \\
\text { encapsulate after 30 } \\
\text { wash }\end{array}$ & $242.23 \pm 0.30$ & \\
\hline
\end{tabular}

From the table it is observed that controlled sample showed highest porosity than other samples. It is interpreted that the surface coating covers the air passage over the surface of the fabric so the air passage in to the fabric was limited. After some wash it is expected to peeled off some coating on the surface of the fabric so that slight improvement in the air permeability was achieved.

\section{Conclusion}

Through this research work Vetiver root extract encapsulated cotton textile has got good mosquito repellent activity of $90 \%$ mosquito repellency activity.This microencapsulation technique provides better wash durability for the treated fabric even after 30 wash cycle, that is even after 30 wash the 
reduction in Mosquito repellency percentage was only $28.5 \%$. Other physical properties such as abrasion resistance due to washing will not statistically significant at $95 \%$ confidence limit. But slight property changes in busting strength and air permeability due to microencapsulation on the textile structure. In over all aspect natural form of extraction of microencapsulated coating is very safe and ecofriendly. This same treatment can also be applied to the oven Fabrics and it can be used as Bed Spreads and Bed Sheets.

\section{References}

1) Maheshwaran $R$, Sathish $S$ and Ignacimuthu $S$ : Larvicidal activity of Leucasaspera (willd) against the larvae of Culexquinguefasciatus Say. And Aedesaegypti L. International J Integrative Biol 2008; 2: 214 - 217.

2) Bernhard, L, Bernhard P, Magnussen P (2003) Management of patients with lymphoedema caused by filariasis in north-eastern Tanzania: alternative approaches. Physiotherapy 89: $743-$ 749 .

3) Farag, S. A., Osama, H., Mohamed, R., \& Mohamed, H. (2011). Development of longerlasting insect repellence cellulosic based curtain fabrics. Materials Sciences and Applications, 2(03), 200.

4) Amer, A., \&Mehlhorn, H. (2006). Larvicidal effects of various essential oils against Aedes, Anopheles, and Culex larvae (Diptera, Culicidae). Parasitology Research, 99(4), 466-472.

5) Brown, M., \& Hebert, A. A. (1997). Insect repellents: an overview. Journal of the American Academy of Dermatology, 36(2),243-249.

6) Rajendran R, Radhai $\mathrm{R}$ and Rajalakshmi V: Development of Mosquito repellent fabrics using Vitexnegundo loaded nanoparticles. Malaya J Biosciences 2014; 1: 19 - 23.

7) MiroSpecos, Garcia J J, Tomesello J, Marino P, Vecchia M D, Defain MV, Tesoriero D, \&Hermida G, Transaction Royal Soc Tropical Medicine Hygiene , 104 (10) (2010) 65

8) Prajapati V, Tripathi AK, Aggarwal KK, Khanuja SPS. Insecticidal,repellent and ovipositiondeterrent activity of selected essential oils against Anopheles stephensi, Aedesaegypti and Culexquinquefasciatus. BioresourTechnol 2005;96:1749-57.
9) Haridasan. P, Gokuldas M, Ajaykumar A P (2017).Antifeedant effects of vitexnegundo 1. Leaf extracts on the stored product pest, triboliumcastaneum h. (coleoptera: tenebrionidae) ,International journal of pharmacy and pharmaceutical sciences, vol 9, issue 3 .

10) Thilagavathi G, Krishna Bala $S$ and Kannaian T:Microencapsulation of herbal extracts for microbial resistance in healthcare textiles. Indian $\mathrm{J}$ Fibre Text Res 2007; 32: 351 - 354.

11) Ramya.k\&maheshwari.v(2014) . Development of eco friendly mosquito repellent fabric finished with andrographispaniculata plant extracts. International journal of pharmacy and pharmaceutical sciences, Vol 6, issue 5.

12) British Pharmacopoeia, Vol. II. Her Majesty's Stationery Of- fice, University Press, Cambridge. Appendix XIE, p. A111,1980.

13) Golja, B., Šumiga, B., \& Forte Tavčer, P. (2013). Fragrant finishing of cotton with microcapsules: comparison between printing and impregnation. Coloration Technology, 129(5), 338-346.

14) Roberts, D. R., Chareonviriyaphap, T., Harlan, H. H., \&Hshieh, P. (1997). Methods of testing and analyzingexcito-repellency responses of malaria vectors to insecticides. Journal of the American Mosquito Control Association, 13(1), 13-17.

15) Christie, K., and Sangeetha, K., 2016, A Comparative study on antimicrobial finish using Pisidiumguajava leaf extraction on cotton, organic cotton and bamboo fabrics. Int. Conf. on Inform. Engg, Mngt and Security, 101-106.

16) Ganesan P, KJ Vardhini, "Herbal treated microbial resistant fabrics for healthcare textiles"Indian journal of natural products and resources, Vol.6(3), 2015.Ganesan P, Ramachandran T, KarthikT,PremAnand V S and Gowthaman T, Process optimization of aervalanata extract treated textile material for microbial resistance in healthcare textiles,Fibre Polymer,2013, 14(10) 1663-1673.

17) Kumar, M., Ruckmani, A., Saradha, S., Arunkumar, R., Lakshmipathy, R., Madhavi, E. and Devi, T., 2014, Evaluation of antiepileptic activity of Vetiveriazizanioides oil in mice. Int. J. Pharm. Sci. Rev. Res., 25(2): 248-251.

18) SakeenaNaikwadi, K.J. Sannapapamma and C.K. Venugopal," Optimization of Vetiver Root Extract 
for Textile Finishing", International Journal of Current Microbiology and Applied Sciences ISSN: 2319-7706 Volume 6 Number 10 (2017) pp. 2009-2022.

19) Senthilkumar. B,"Study on antimicrobial effectiveness of sliver nano coating over cotton fabric through green approach" International Journal of Pharma Sciences and Research (IJPSR), Vol. 7 No. 9 Sep 2016.

20) Haridasan. P, Gokuldas M, Ajaykumar A P (2017).Antifeedant effects of vitexnegundo 1. Leaf extracts on the stored product pest, triboliumcastaneum h. (coleoptera: tenebrionidae) ,International journal of pharmacy and pharmaceutical sciences, vol 9, issue 3 .

21) Thilagavathi G, Krishna Bala $S$ and Kannaian T:Microencapsulation of herbal extracts for microbial resistance in healthcare textiles. Indian J Fibre Text Res 2007; 32: 351 - 354.

22) Golja, B., Šumiga, B., \& Forte Tavčer, P. (2013). Fragrant finishing of cotton with microcapsules: comparison between printing and impregnation. Coloration Technology, 129(5), 338-346.
23) Dr. T. Ramachandran, R. Rajendran, Antimicrobial textiles- an overview.

24) Anon (1976) Vetiver. In: Wealth of India, vol X. Publication \& Information Directorate, Council of Scientific and Industrial Research, New Delhi, pp 451-457.

$25)$ "Dengue and severe dengue Fact sheet $\mathrm{N}^{\circ} 117 "$ ". WHO. May 2015. Archived from the original on 2 September 2016. Retrieved 3 February 2016.

26) Kularatne, SA (15 September 2015). "Dengue fever". BMJ (Clinical research ed.). 351: h4661. doi:10.1136/bmj.h4661. PMID 26374064.

27) Nelson Textbook of Pediatrics: The field of pediatrics. Elsevier Health Sciences. 2016. p. 1631. ISBN 9781455775668. Archived from the original on 10 September 2017.

28) East, Susie (6 April 2016). "World's first dengue fever vaccine launched in the Philippines". CNN. Archived from the original on 18 October 2016.

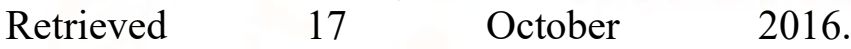

